wintered at the Molodezhaya station; and a Soviet glaciologist wintered at the US McMurdo base. A regular exchange of information was maintained with the British, Australian, US and Japanese Antarctic stations.

In contrast to these large-scale undertakings, a modest expedition of six skiers set off at the end of April from Wrangel Island to make their way over the ice to the drifting Severnyi Polyus-23 icefloe station. This expedition was somewhat misleadingly described by TASS as a "sports expedition", and although its close association with the newspaper of the young Communist movement at first suggests heroic adventure rather than serious research, this was not the case. One of the main aims of the expedition was the study of problems of psychological compatibility in a small team working under extreme conditions. The rations of the party were based on those of cosmonauts, and the results of the project may be intended for use in the study of the potential personality conflicts and stresses which may arise aboard a space-station or in long space flights.

\title{
correspondence
}

\section{More on Paradisia}

SIR,--It is good to see you airing the Paradisia/Dominatia relationship in your columns (May 20, page 178). As a labourer in a different corner of the vineyard from Professor Brock, I find myself with another perspective. My concern is the training given to young Paradision Scientists (PhD students and post-doctoral fellows) when they visit Dominatia.

I think it is fair to assume that most Domination Scientists would like to help Paradisia develop and operate a self-supporting research effort-suited both to the intellectual and the material needs of the country-as soon as possible. I sometimes wonder, however whether they set about things the right way. There may be States where the system to be aimed for closely resembles one to be found in Western Europe or the USA, but such places must form a small minority.

The normal situation is one where at no time in his working life is today's young Paradisian academic likely to have the resources either of time (because of a heavy teaching commitment) or money to undertake research in a way comparable with his Domination counterparts. His high intelligence, diligence and determination cannot alter this fact, and it does no-one any good to attempt to ignore or disguise the situation. The ideal training for an individual of this kind is therefore different from that generally offered to natives of Dominatia. It needs, above all, to encourage independence and self-reliance (hard these days when research projects are often scarcely comprehended by a student before he starts to write his thesis). Experimental ingenuity with scarce resources and self-criticism allied with the optimism which attempts to cut a coat according to cloth (rather than weeping and complaining that good cloth is unavailable) are also essential.

In all of this Dominatia can help, but to be really useful involves more than treating students from Paradisia in the same way as their British counterparts. Doing so sometimes produces a fine scientist by Domination standards, but also someone who is discontented and unwilling to adapt to a different environment in the Paradisia to which he returns. Ideally a Domination supervisor will take the trouble to learn about Paradisia-its scientific research facilities, the peculiarly Paradisian problems which science might help to solve, even the government policies relevant to science and higher education. He needs to view the collaboration as part of the continuing development of his Paradisian colleague's life, as well as a contribution to his own research group's output. He should even, perhaps, begin to question whether his own view of the purpose of research, and what is worthwhile research, is the only tenable one. It may be that work which is not publishable in his own favourite journal can nonetheless provide important answers in a different context. In our joint efforts to help Paradisia, it is not only the Paradisians who need to learn.

\section{Geoffrey R. Penzer}

Cairo,

Egypt

\section{$\mathrm{PhD}$ in evolution}

SIR,-Your Editorial "PhD in evolution" (May 27) seems in its penultimate paragraph to reveal a general misconception about the purpose and nature of $\mathrm{PhD}$ research. It is assumed that $\mathrm{PhD}$ research should provide training for scientists going into industry. This, however, is not the case. The chief motive of a student going to a university science department to do research should be a desire to take part in the advancement of science. If he really wants to be trained for industry, he should go into industry, where he will receive a better training for that particular job than universities can provide. It is true that industry sometimes, not to say often, finds that $\mathrm{PhD}$ research has provided skills and attitudes which are useful to it, but this is not the primary purpose of $\mathrm{PhD}$ research.

Distorting university postgraduate research to provide a training explicitly and directly useful to industry will harm the progress of fundamental science and, conversely, a postgraduate research student entering a science department should expect to learn about fundamental research and the particular activities that entails. If he expects a course aimed at preparing him for industry he is embarking on university research with the wrong motive.

It may be said that, if $\mathrm{PhD}$ research is not providing a training for industry, there should not be many science research students. I think this view is correct; I believe university scientists should take on a research student only if he has a genuine desire to carry out original work in science and recognises that this may not help him to get a better job outside university.

These comments apply to PhD research in "pure" science departments; I believe the situation may be different in engineering and technological departments.

\section{A. C. Rose-InNes}

Department of Physics and Electrical Engineering,

University of Manchester Institute of Science and Technology,

Manchester, UK

\section{The real AI}

SIR,--Whilst bemoaning the antihumanistic potential of artificial intelligence (May 13, page 171), it is particularly inappropriate to make use of the long established and well recognised acronym for artificial insemination.

$$
\begin{aligned}
& \text { Yours faithfully, } \\
& \text { Darrell H. ThORPE }
\end{aligned}
$$

London, UK 